\title{
Communication entre médecin et patient
}

Ursina Pally Hofmann

Dr iur., avocate, Service juridique
Correspondance: Dr Ursina Pally Hofmann FMH / Service juridique Elfenstrasse 18 CH-3000 Berne 15 ursina.pally[at]fmh.ch
La communication entre médecin et patient n'est pas une problématique récente: tant la Fondation Sécurité des patients que l'ASSM ont édité des publications à ce sujet. Malgré cela, elle est néanmoins souvent un motif d'insatisfaction pour médecins et patients.

La FMH, la Fondation Organisation suisse des patients (OSP), la Fédération suisse des patients et l'Association suisse d'assurances préconisent également une communication ouverte entre médecin et patient. L'Association suisse des médecins avec activité chirurgicale et invasive (fmCh), H+ Les Hôpitaux de Suisse, la Société suisse de médecine interne générale et l'Association des médecins-assistant(e)s et chef(fe)s de clinique (ASMAC) partagent aussi cette préoccupation. C'est pourquoi ces associations, sous la houlette de la FMH, ont consigné les points essentiels de la communication entre médecin et patient dans une brochure disponible sous forme électronique sur le site Internet www.fmh $\mathrm{ch} \rightarrow$ Service $\rightarrow$ Droit.

Cette brochure vise à donner aux médecins un aperçu de la manière dont ils peuvent gérer la communication avec leurs patients. Pour ces derniers, elle précise ce qu'ils sont en droit d'attendre de leur médecin. Les associations participantes sont convaincues qu'une bonne communication influe de manière positive sur la satisfaction des patients, et ce dans l'intérêt de tous.

Le document contient des recommandations applicables dans trois situations:

\section{Communication entre médecin et patient}

Recommandation en cas d'incident médical

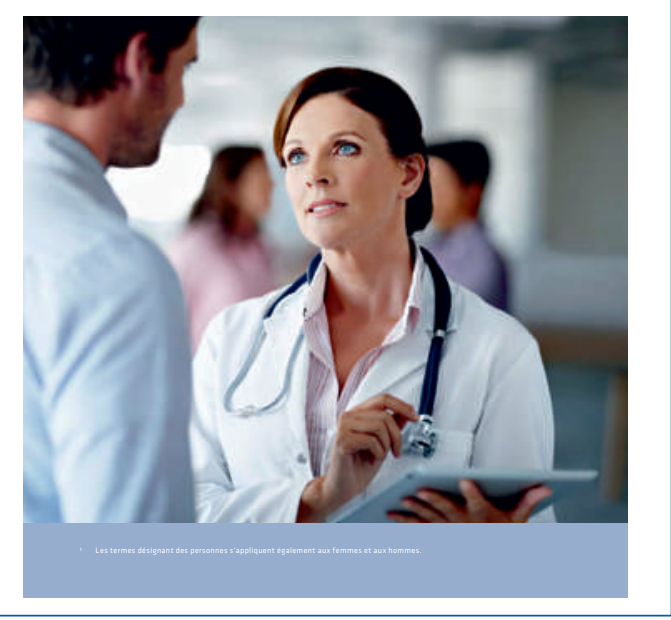

Dans l'intérêt de tous: une bonne communication entre patient et médecin.
1. Avant le traitement, il s'agit de donner au patient des informations réalistes sur les chances de succès. Cela implique de lui expliquer les risques liés au traitement, de ne pas lui garantir que celui-ci sera couronné de succès, et de rectifier les attentes irréalistes du patient. Bien entendu, le patient doit aussi être informé, avant l'intervention, des autres aspects de cette dernière. Ce ne sont toutefois pas ces aspects-là que nous traitons. En l'espèce, il s'agit avant tout de ne pas susciter chez le patient des attentes excessives. En effet, celui-ci risquerait alors d'être déçu même si le traitement a été administré de manière diligente.

2. La brochure définit l' «incident» comme un écart du cours normal des choses, sans connotation liée au droit de la responsabilité civile. En cas d'incident, il faut dans un premier temps répondre aux éventuelles questions du patient. Dans un second temps, le médecin doit informer le patient des faits liés à l'incident, dans la mesure où il en a connaissance. Il est important pour le patient de connaître les répercussions de l'incident sur son état de santé et les traitements qui lui permettront de préserver, voire d'améliorer, ce dernier. Le médecin ne doit toutefois pas s'engager au point de promettre le versement de dommagesintérêts ou de reconnaître une faute, car il faut tout d'abord élucider les aspects liés au droit de la responsabilité civile. A cet égard, outre les aspects médicaux, il convient également de prendre en compte les aspects juridiques liés au cas. Une appréciation du cas n'est possible qu'après avoir procédé à une clarification minutieuse des faits sous l'angle médical et à la qualification juridique de ces faits. Il incombe à l'assurance responsabilité civile de mener à bien ce processus.

3. Le médecin qui assure la suite du suivi ne doit porter de jugement sur le traitement précédemment administré par un autre médecin que si le patient lui demande expressément un deuxième avis ou s'il est désigné en qualité d'expert. Le médecin chargé de donner un deuxième avis n'est en mesure de procéder à une évaluation objective que s'il dispose de tous les documents nécessaires à cette fin. Une évaluation hâtive et infondée d'un traitement administré par un autre médecin peut donner lieu d'une part à des griefs injustifiés à l'égard du premier médecin et, d'autre part, exposer le second médecin à une procédure disciplinaire.

La brochure a fait l'objet d'un envoi groupé par mail à l'ensemble des sociétés de discipline médicale. Elle est en outre publiée sur les sites Internet des associations participantes. 